\title{
DIE VERBAND TUSSEN VAK- RIGLYNE, VAKAANBIEDING EN PRESTASIE BY GROEPE B CUR I-STUDENTE AAN DIE UNIVERSITEIT VAN PRETORIA GEDURENDE 1985 EN 1986
}

\author{
Christine van Velden
}

Inleiding

Dic vraag word dikwels gevra wat die nd is tussen vakriglyne en vakaanbieding en 'n student se prestasie. Word die effek van vakriglyne en vakaanbieding oorbeklemtoon of nie? Die antwoord op diè vraag is uit die aard van die saak van die allergrootste belang vir enige dosent.

Dr. S.P.T. Malan skryf in hierdie verband

"Die sin van 'n student se

onderrigaktiwiteit is daarin geleë dat studente effektief moet leer. Alhoewel persoonlike kontak tussen leerder en leermeester 'n primêre kenmerk van residensièle Universiteite is, is dit voor-diehand-liggend dat hierdie kontak nie die enigste geleentheid is waartydens leer plaasvind nie en waarskynlik is dit ook nie die mees effektiewe leersituasie nie. Vir vandag se leerbenadering is doclgerigte akademiese beplanning van die uiterste belang en dit begin met wetenskaplikverantwoordbare kurrikulering om clike doelstellings en doelwitte te bepaal vir die leerinhoud van vakke. $A k$ ademiese beplanning vind uiteindelik neerslag in 'n studiebehandeling as bestuursinstrument waardeur die dosent die student se selfstudie-aktiwiteite op 'n gerigte wyse bestuur. Die studie handleiding lei die student om te weet watter leerdoelwitte bereik moet word."

As bewys vir die korrektheid van Malan se stelling word verwys na die volgende:

- 'n Ondersoek gedoen deur M. Nelson het aangedui dat studente wat slegs 'n lesing oor 'n onderwerp ontvang het, nie so goed presteer het as studente wat saam met die lesing ook 'n handleiding ontvang het nie. ${ }^{2}$

- 'n Ondersoek gedoen deur S.B. Fiel en $K$. Glanz by mediese studente het aangedui dat gereëlde lesingbywoning nie noodwendig ' $n$ bepalende invloed op die akademiese prestasie van die student het nie. ${ }^{3}$

- H.W. Jorissen het geskryf:

"Die dosent kan deur studiehandleidings te implementeer die onderrigleergebeure suksesvol orden, studente se

\section{Summary}

Research done on groups of B Cur I students at the University of Pretoria proved that their achievement correlated with their assessment of the guidelines on the subjects but not with their assessment of the presentation thereof. This is in accordance with the findings of other research.

\section{Opsomming}

in Ondersoek op groepe B Cur I studente aan die Universiteit van Pretoria het bewys dat hul prestasie korreleer met hul evaluering van die vakriglyne, maar nie met hul evaluering van die vakaanbieding nie. Die bevindinge is in ooreenstemming met ander navorsing.

betrokkenheid by leerinhoud en hul selfstudie daarin verhoog en leerinhoud bemeestering deur doelwitbereiking bereik. 'n Verantwoordbare studiehandleiding verseker dat 'n dosent planmatig, georganiseerd en bowenal doelwitgerig onderrig. 'n Studiehandleiding begelei en gee progressief rigting aan sy studie, besprekingsklasse en sy selfstudie. ${ }^{4}$

\section{Metode}

Die opnamemetode van navorsing is gebruik. Die B Cur l-studente aan die Universiteit van Pretoria is gevra om gedurende 1985 en 1986 die vraelys in te vul. Gedurende beide jare was daar 29 B Cur I-studente.

In die vraelys is die studente versoek om:

- aan te dui of daar vakriglyne vir elke vak bestaan het en of die vakriglyne wat wel bestaan het, goed of swak was.

- aan te dui of die vakaanbieding stimulerend, duidelik of vaag was

Gedurende 1985 het die kurrikulum uit sewe vakke bestaan. Een vak het gedurende 1986 in die eerste jaar verval, dus het die kurrikulum toe uit ses vakke bestaan
Die Kruskal-Wallis toets is gebruik om betekenisvolle verskille aan te dui. Waar $p<0,05$ is dui dit op ' $n$ betekenisvolle verskil.

\section{Resultate}

Die resultate van die opname in die onderskeie jare is aangedui in staafdiagramme wat eerstens die studente se evaluasie volgens die vraelyste m.b.t. die besondere vak en daarna hul prestasie in die besondere vak uiteensit. Die sewe vakke in 1985 is aangedui as A-G. $\ln 1986$ het vak E verval, dus word dit as sodanig in 1986 uitgeskakel.

Bespreking van Figure I en 2 (Sien Bl. 2)

- By vakke A, B, C en D korreleer die studente se evaluering van die vakriglyne met die studente se prestasie.

- By vakke $\mathrm{F}$ en $\mathrm{F}$ korreleer die studente se evaluering van die vakriglyne nie met die studente se prestasie nie. Geen betekenisvolle verskil kon by vak $\mathrm{E}$ aangedui word nie $(P=0,9)$.

- By vak $G$ korreleer die studente se evaluering van die vakriglyne met die studente se prestasie, maar geen betekenisvolle verskil kon aangedui word nie $(P=0,3)$.

Bespreking van Figure 3 en 4

- By vakke A, B, F en G korreleer die studente se evaluering van die vakriglyne met die studente se prestasie.

- By vakke $C$ en $D$ korreleer die studente se evaluering van die vakriglyne met die studente se prestasie, maar geen betekenisvolle verskil kon aangedui word nie (By vak $C$ is $P=0,3$ en by vak $D$ is $P=0,1$ )

Bespreking van Figure 5 en 6 (Sien Bl. 3)

- By vakke A, B, C, D, E, F en G korreleer die studente se evaluering van die vakaanbieding nie met die studente se prestasie nie. Geen betekenisvolle verskil kon by een van die vakke aangedui word nie (Die P-waardes vir die onderskeie vakke is soos volg: Vak $A: P=0,4$ Vak $B: P=0,5$ 


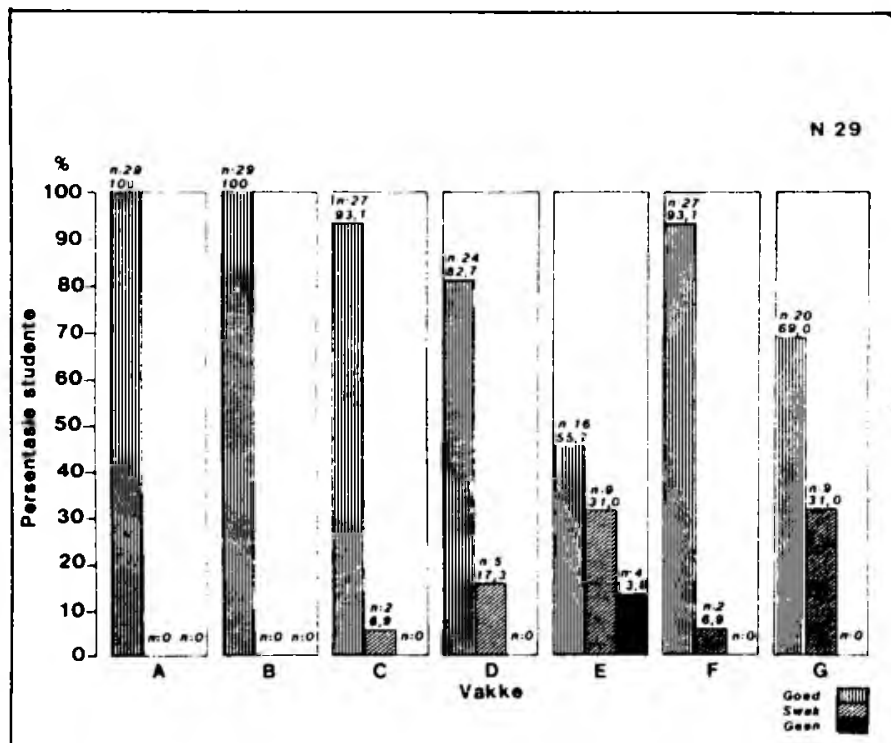

Fig. 1. Proporsie studente se evaluering van vakriglyne per vak vir B. Cur I U.P. 1985.



Fig. 2. Studente se prestasie volgens evaluering van vakriglyne per vak vir B. Cur I U.P. 1985.

Vak C: $P=0,1$

Vak D: $P=0,3$

Vak E: $P=0,4$

Vak F: $P=0,4$

Vak G: $P=0,2$ )

\section{Bespreking van Figure 7 en 8 (Sien BI. 3)}

- By vakke A en B korreleer die studente se evaluering van die vakaanbieding met die studente se prestasie, maar geen betekenisvolle verskil kon aangedui word nie (By beide vakke is $P=0,4$ ).

- By vakke C, D, F en G korreleer die studente se evaluering van die vakaanbieding nie met die studente se prestasie nie, en kon geen betekenisvolle verskil aangedui word nie. (Die P- waarde vir die onderskeie vakke is soos volg:

Vak C: $P=0,4$

Vak D: $P=0,4$

Vak $F: P=0,8$

Vak $($ : $: P=0,9$ )

\section{Gevolgtrekking}

A Vakriglyne

- By die 1985-groep korreleer die studente se evaluering van die vakriglyne by vier van die sewe vakke met hul prestasie.

- By die 1986-groep korreleer die studente se evaluering van die vakriglyne by vier van die ses vakke met hul prestasie.

\section{B Vakaanbieding}

- By die 1985-groep korreleer die studente se evaluering van die vakaanbieding nie by een van die vakke met hulle prestasie nie.

- By die 1986-groep korreleer die studente se evaluering van die vakaanbieding nie by een van die vakke met hul prestasie nie.

Die navorsing dui dus aan dat die studente se prestasie eerder korreleer met hul evaluasie van die vakriglyne as met hul evaluasie van die vakaanbieding.

Die korrektheid van die stellings deur

Malan word dus deur die navorsing gestaaf, en die stellings is dus ook van toepassing op hierdie groep $\mathrm{B}$ Cur-studente. 


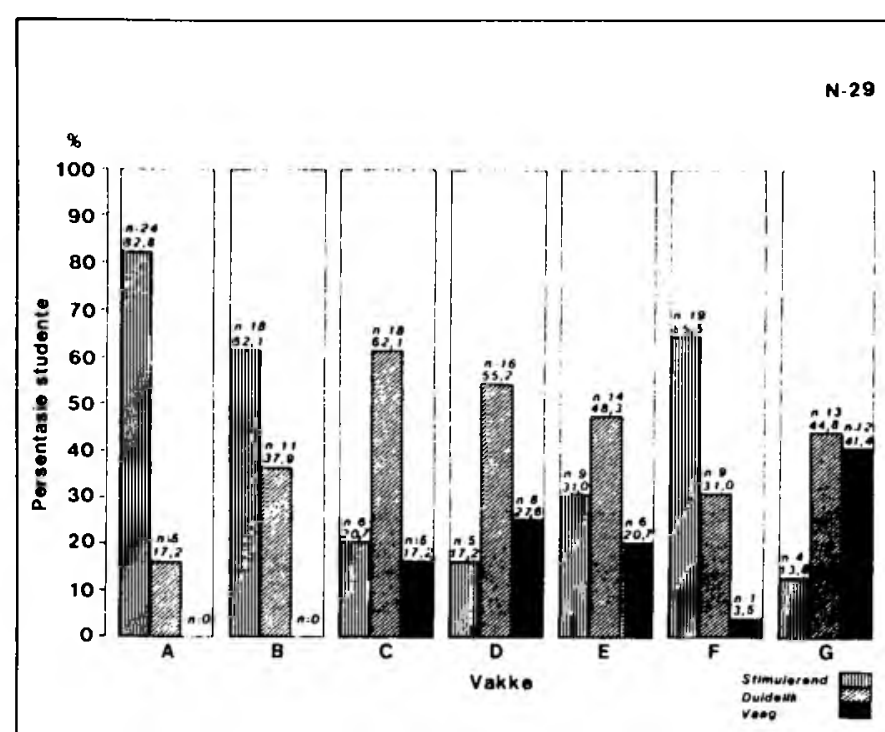

Fig. 5. Proporsie studente se evaluering van vakaanbieding per vak vir B. Cur I U.P. 1985.

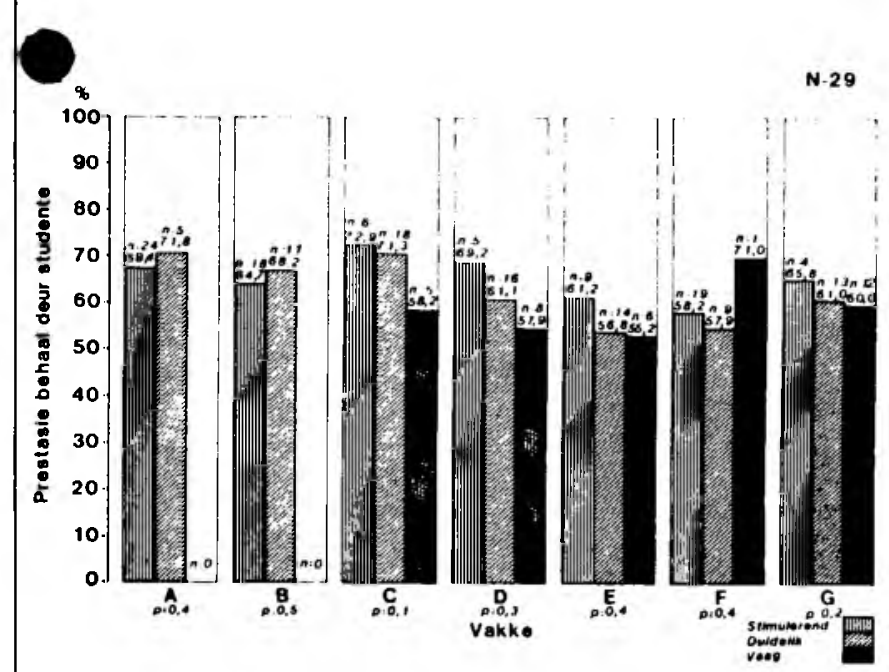

Fig. 6. Studente se prestasie volgens evaluering van vakaanbieding per vak vir B. Cur I U.P. 1985.

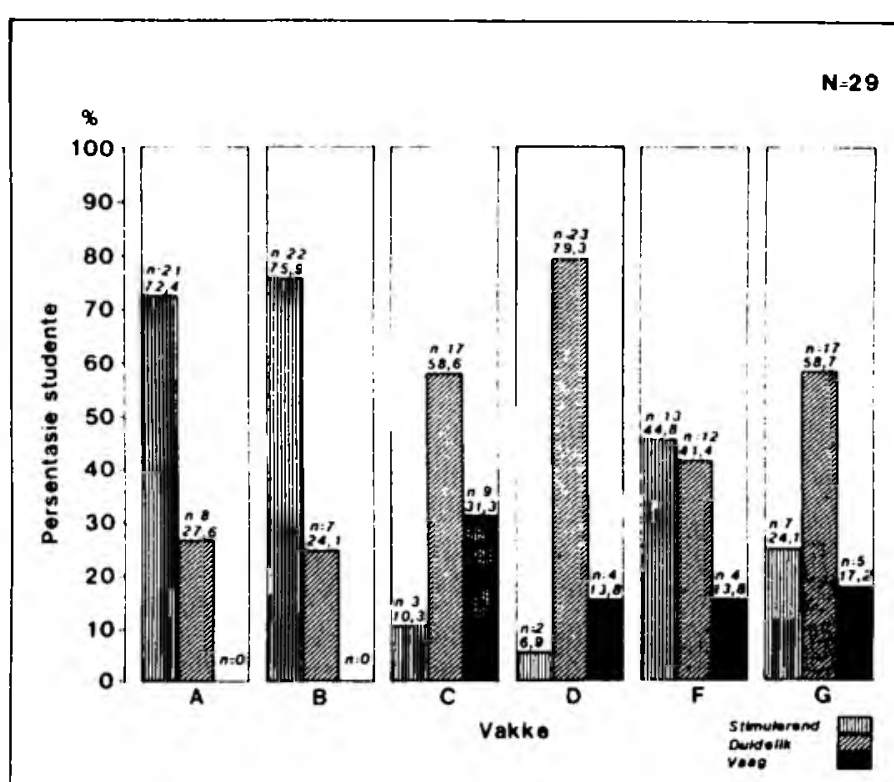

Fïg. 7. Proporsie studente se evaluering van vakaanbieding per vak vir B. Cur I U.P. 1986.

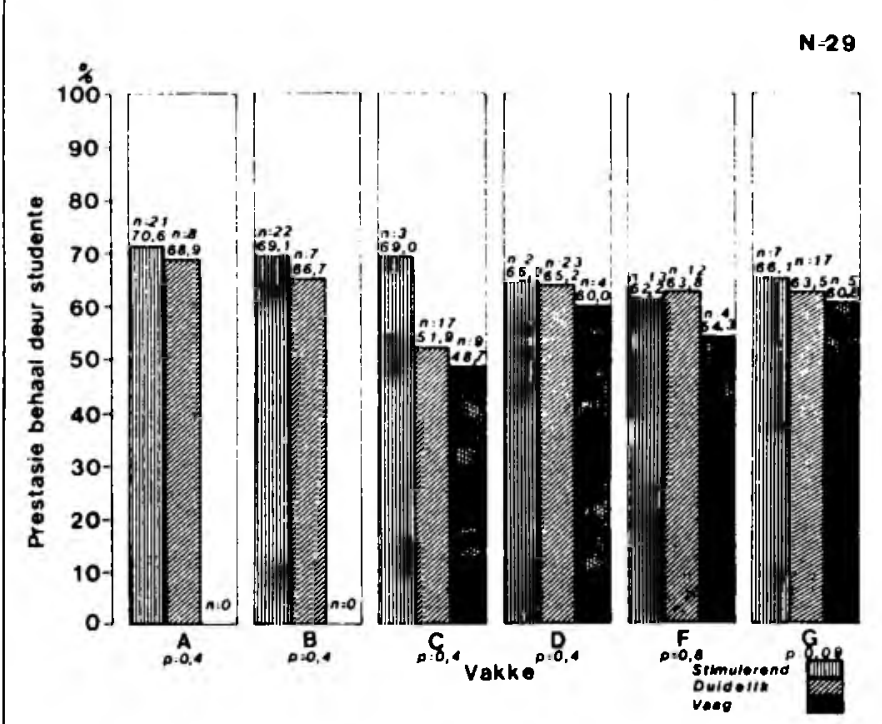

Fig. 8. Studente se prestasie volgens evaluering van vakaanbieding per vak vir B. Cur I U.P. 1986.
Slot

Alhoewel die belang van formele lesings nie betwyfel kan word nie, onder andere vanweë die waarde van persoonlike kontak tussen die dosent en student, is dit dus duidelik dat die vakriglyne met spesifieke verwysing na die studiehandleiding, 'n besondere belangrike rol speel wat nie oorbeklemtoon kan word nie.

\section{VERWYSINGS}

1. Malan S.P.T. 1987. Leergeleenthede: 'n
Nuwe Dinamika. Tukkie Onderrig, nr. 2 : Julie, 1.

2. Nelson M. 1984. CPR Instruction: Modular Versus Lecture Course. Ann Emerg Med, nr. 13: Feb, 118-121.

3. Fiel S.B., Glanz K. 1984. Effect of Attendance of Lecturers on Medical Performance. $J$ Med Educ, nr. 59: Jun, 516-518.

4. Jorissen H.W. 1984. Die Studiehandleiding as wyse om akademiese selfwerksaamheid by studente te bevorder. UP-Dosent, nr. 5: Julie, 14-21.

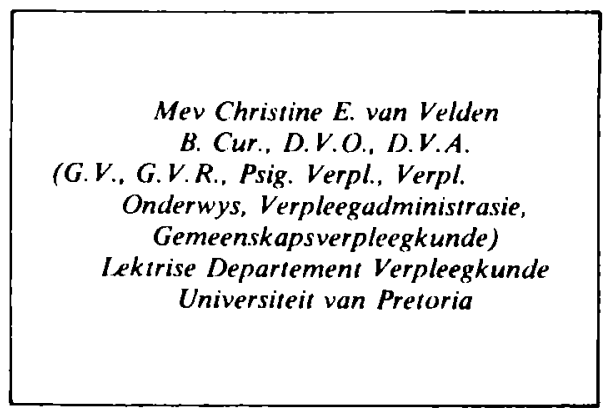

